\title{
FORMATION OF AN INVESTMENT PORTFOLIO ADEQUATE FOR STOCHASTICITY OF PROFIT POSSIBILITIES
}

\author{
Aleksandras Vytautas Rutkauskas ${ }^{1}$, Jelena Stankevičienė ${ }^{2}$ \\ Vilnius Gediminas Technical University Sauletekio al. 11, LT-2040 \\ Vilnius, Lithuania.E-mail: 'ar@vv.vtu.lt; ${ }^{2}$ elenast@vv.vtu.lt
}

Received: 9 August, 2002

\begin{abstract}
The paper deals with the conception of integrated bank assets and liabilities portfolio adequate to stochastic nature of assets profitability and liabilities expenditures. Two interconnected situations are considered. Firstly, the principles of construction of an investment portfolio, adequate to stochastic nature of an investment yield arc considered. Further, the idea of consideration and optimal selection of integrated assets and liabilities portfolio is considered. These problems are solved on the basis of the authors' idea of investment portfolio adequate for stochastic nature of investment portfolio and the numerical solution of such problems, which is briefly presented.
\end{abstract}

Keywords: Integral portfolio of assets and liabilities; Currency portfolio; Utility function; Imitative technologies of portfolio formation and optimization.

\section{Introduction}

Modern (H. Markowitz) investment portfolio [1] today became the background of modern investment theory, and main object of investigations, searches, and improvements. There arc two main scantiness of modern investment portfolio, which should finally find one or another solution. First of all, average - standard deviation portfolios don't let to value the reliability of results. At the moment while forming investment portfolio of the institution with this method, features of liabilities are not taken into consideration. In this paper some variants of modern investment portfolio developments are suggested, in order to gain its adequacy for the stochastic nature of investment profitability, also by combining features of assets and liabilities, in order to assure optimal assets and liabilities portfolio for the institution.

The aim of the paper. Objectifying the conception of integral assets and liabilities portfolio and opportunity analysis of formation methods of such portfolio and its practical use.
Object of the investigation. Object of the investigation is development of investment instruments.

Methods of the investigation. To prepare this paper imitative formation technologies, analogies and analytical-systematic scientific literature analysis methods were used.

\section{Portfolio anatomy and it's analytical opportunities}

Portfolio - when we keep in mind investment - is a set of kinds of assets, depending to some kind of institution or individual, formation principles of which are directed to variety assets and use of set proportions, to reach usefulness for the portfolio owners [2]. Financial portfolio - is a set of financial assets. The truth is, content of portfolio can be very different. Besides assets (rights) portfolio there can also be liability portfolio, or even mixed.

Very often it is said that, portfolio consists of assets $A_{1} A_{2}, \ldots, A_{n}$, then we say that portfolio has a structure $\mathrm{w}_{\mathrm{p}} \mathrm{vv}_{2}, \ldots, w_{n}\left(w,>0, \mathrm{w},,+\mathrm{w}_{2}+\ldots+\mathrm{w}=1\right)$ and 
portfolio value $v=w_{1} a_{1}+w_{2} a_{2}+\ldots+w_{n} a_{n}$, where $a$, is value of asset $i$.

Security portfolio theory - is a system of knowledge, with the help of which investor can strive for largest expected profit, from different - risky and not risky set of securities, taking into consideration one's opportunities to manage risk. The main corner problems, which are solved by portfolio theory - are defining of possible portfolio complexity, finding of portfolio efficiency line, choosing of optimal portfolio for every investor [3].

So, using portfolio conception we describe not a set of investments on the whole, but a structural set, which best coincide portfolio investment opportunities and institution or individual demand for income and opportunities to manage income risk. By the way, the idea of portfolio concept, had started with investment decisions, and comprises not only assets and liabilities as portfolio elements, but strategy, criteria and other portfolios are also analyzed.

To realize the idea of portfolio (goal, which is expected to be reached when portfolio is formed) sometimes complex stochastic programming, statistical formation and other methods must be used [4]. In its turn portfolio decisions logic is sufficiently original and very often named as portfolio decisions can supplement stochastic programming and other probability methods. In order to understand easier portfolio methodology, let's analyze in details the so-called modern or classical portfolio, and further discussing adequate for investments stochastic nature portfolio and integral assets and liabilities portfolio distinctive features.

In order to understand easier the solving of these problems, it is important to get deeper in geometry of the problems, or even better in plane surface, in which decision criteria and also decisions are illustrated. It is common, that in ordinate axis portfolio profitability average values arc put, and on abscise axis - instability (risk) measure of the same profitability, it is average standard deviation. So, in different coordinate axis the same probability distribution average and standard deviation are put. After choosing the set of assets with known values of profitability and average standard deviation and under the condition that in the portfolio of investor each of the assets can possess a part, which vary between 0 and 1 , we will have the so called set of all possible portfolios (Fig 1). So, possible portfolio complexity, or set of investor choices is defined.

Such a form of possible portfolio set is obtained because of mathematical random variables and their leverage sums features. In a classical portfolio line YB

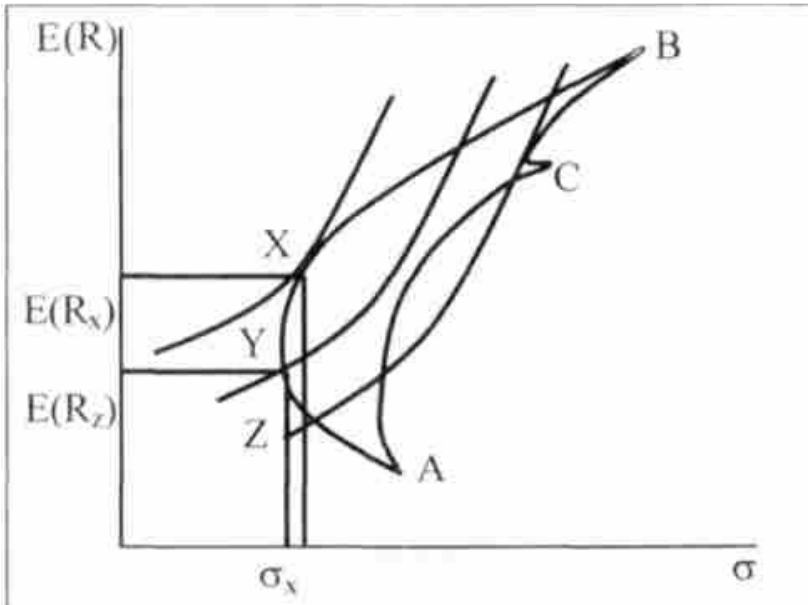

a. The selection of the best alternative from all possible

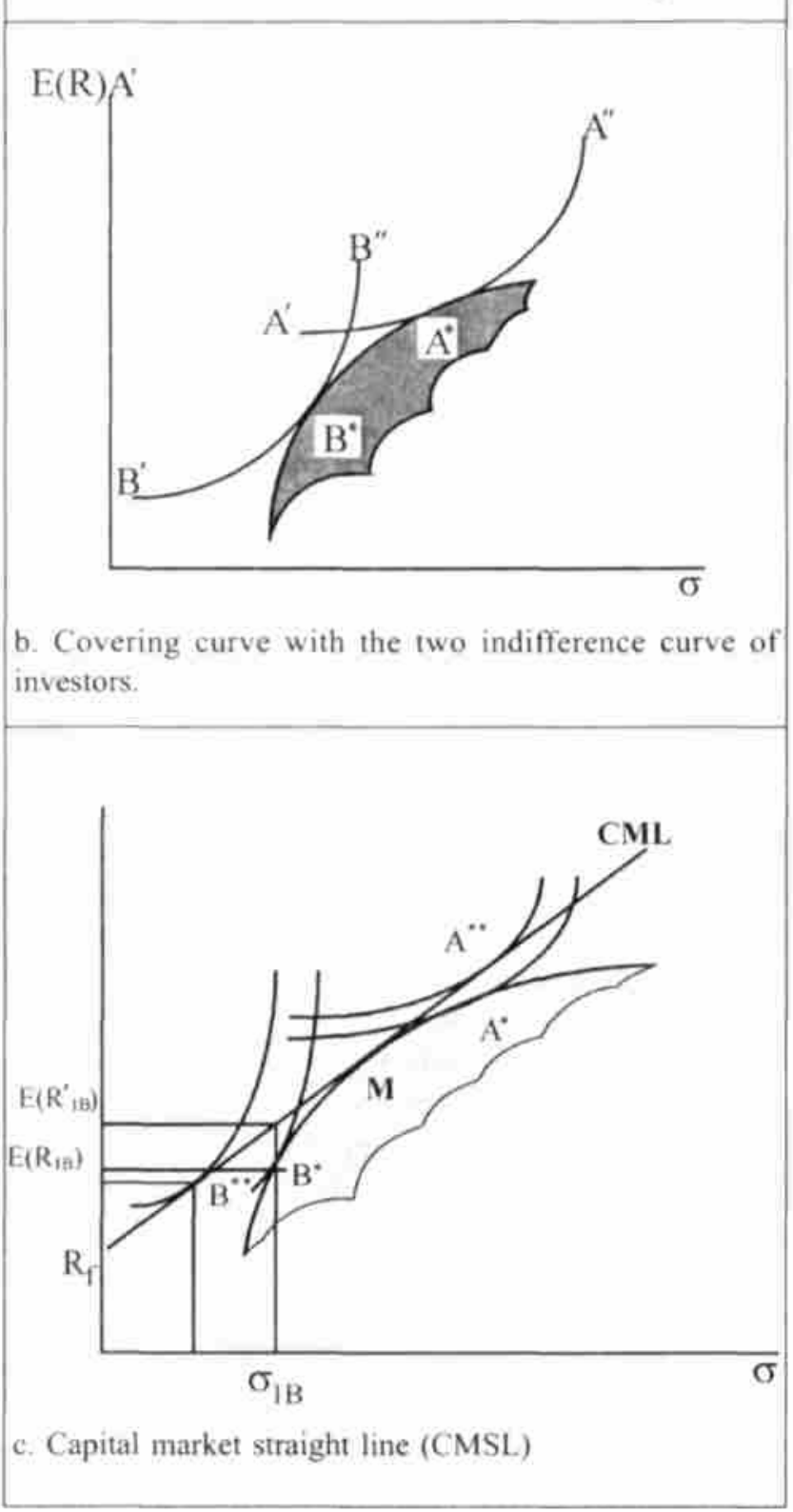

Fig 1. Selection variants of portfolio solutions 
is called efficiency line and this line also is part of convex curve AB. These lines have exceptionally important value discussing and analyzing separate portfolio features. Efficiency line is maximum line of profit average of possible portfolios, which have some level of risk.

It was already mentioned, that mission of portfolio as investment theory instrument - is finding of investment set structure having special features - $\mathrm{w}, \mathrm{vv}_{2}, \ldots$, $w_{n}$, that let to maximize portfolio profitability, at a given risk level, or minimize risk, at a given profit level. For the further understanding, it is important to remember common risk distribution into systematic and nonsystcmatic risks. The known fact is, that for the sufficiently large quantity of investments in the portfolio, practically characteristic feature is systematic risk. That is the part of risk, which is characteristic for all (country, region, world) economic system. Further only part of systemic common risk will be analyzed.

The last of the three problems, solved with the help of portfolio theory is selection of optimal portfolio for a separate investor from possible set of portfolios that is selection of portfolio, which is on efficiency line. It is very important to emphasize, that in the portfolio theory investments (and their sets) are analyzed in an atmosphere not impartial from investors possibilities, but taking into consideration utilization of investor. That is exceptional feature of portfolio theory maximizing criteria.

In a modem portfolio theory it is approved to use simplified change of utilization function - indifference curves. The conception of indifference curve, appeared from consuming theory, where it expresses such a combination of two goods, which are both useful for a consumer, and in portfolio theory define both accepted profit and risk derivative for investor. In the Fig 1 we can see that investor should choose himself the most useful portfolio, taking into consideration possible set of portfolios and its utility (indifference) function.

To illustrate portfolio theory maximization principles orientation into common utility increase, can help Fig $\mathrm{lb}$, which illustrate how investors having different indifference curves $\mathrm{A}^{\prime} \mathrm{A}^{\prime}$ and $\mathrm{B}^{\prime} \mathrm{B}$ ", select different optimal portfolios (maximizing their utility), and maximizing common investments formation utility as well.

Evidently, that such a portfolio optimization logic is correct only when in portfolio there are only risky investments. In this way that is correct, optimal solution belong to efficiency line and is in the net of indifference map. That is point $\mathrm{X}$ in a Fig la and points $\mathrm{A}^{*}$ and $\mathrm{B}^{*}$ in the Fig $\mathrm{lb}$.
But this precondition existing only from risky investments docs not reveal real investor opportunities in the world of investments, where there also exist not risky securities, as governmental bonds. And if this happens, then it means, that there is such a possibility for the investor to reach higher utility level, than that in the points $\mathrm{A}^{*}$ and $\mathrm{B}^{*}$. They are points $\mathrm{A}^{* *}$ and $\mathrm{B}^{* *}$ in the indifference maps of investors. This situation is illustrated in the Fig lc.

Norm of not risky short-term governmental securities is shown as point $R_{f}$ in certain conditions any investor can distribute his capital freely between risky investment shown in the point $M$ on efficiency line and nonrisky securities - in the point $R_{r}$

To describe this process we get such a linear expression:

$$
\omega_{\mathrm{m}} \mathrm{M}+\left(1-\omega_{\mathrm{m}}\right) \mathrm{B}
$$

here:

$M$ - parameters of risky investments; $B$ parameters of nonrisky investments; $\omega_{\mathrm{m}}$ part existing in risky investments.

All points that are obtained as linear combination of risky and nonrisky securities arc lying on straight line, which connect $\mathrm{R}_{\mathrm{f}}$ and $\mathrm{M}$ points. If investor takes a priority smaller risk, then position will be closer to the point $R_{f}$ if investor takes as apriority for a larger risk, than position will be closer to a point $\mathrm{M}$ or upper point M.

Let's go back to the investor B, in order to understand the principle of selection. If there are no opportunities to invest into nonrisky assets, an investor selects portfolio $B^{*}$ with risk $\sigma_{1 B}$ and expected profit $E\left(R_{1 B}\right)$. When there is an opportunity to obtain nonrisky assets, investor $B$ can select between $M$ and $B$, so that in the same risk, he could get bigger profit $\left.\mathrm{E}\left(\mathrm{R}^{\prime}\right) \mathrm{B}\right)$. In fact, investor $\mathrm{B}$, on the bases of his indifference map, should take as a priority point $\mathrm{B}^{* *}$, in which profit is insignificantly decreased, but risk - decreased significantly. According to the precondition investor $\mathrm{B}$ gives priority to this position (insignificantly smaller profit, but significantly smaller risk), because indifference curve that intersects $R_{f} M$ in the point $B^{* *}$ is of indifference curve of higher level than curve intersecting point $\mathrm{B}^{*}$. This shows investor indifference curve graphical view as well. Let's go back to investor A. It was said that he accepts larger growth of risk. His indifference map shifts his selection to the left from the point M. Now he doesn't distribute capital between $\mathrm{M}$ and $\mathrm{B}$. Instead of that, he borrows with the not risky price $\mathrm{Rf}$ these means and those that already has he invests so that could reach point $\mathrm{A}^{* *}$. 
As it is known, straight line is evaluated as straight line of capital market (SLCR). Clear detachment of risky and nonrisky capital let us to get result, which is known as J. Tobin separation theorem [5]. Now let's discuss again portfolio $\mathrm{M}$. Investor A uses this risky assets portfolio. Investor B does it as well. Of course, when advantages of this portfolio are known, any investor will include this portfolio into his investment combination. That is the only one equilibrium portfolio, which every risk averse investor will have. By saying risk avoiding or risk averse investors, it's not kept in mind, that investor absolutely doesn't accept risk; it means, that in the case, when there arc two investments with similar profits, but with different risks, priority will be given for a smaller risk. So portfolio $\mathrm{M}$ become market portfolio and under equilibrium condition has to include all possible risky investments in such relationship, that it could proportionally represent for all investments.

\section{Formation and usage of the portfolio adequate for profit stochastisity}

Scantiness of traditional portfolio analysis scheme and opportunities to develop. Classical portfolio analysis [6], management or other using scheme in its final expression is sufficiently clear and convenient for a practical use. But the way to this simplicity is not so easy. Efficiency curves as well as covering curves functional expression, which must be necessary used in a practical portfolio application, is not obvious in common way. Meanwhile, portfolio formation and management require effective different possible portfolio states, which arc on efficiency line estimating, description of the states interactions, or analyzing other portfolio features. Moreover, portfolio solutions must be obtained, when separate portfolio assets, and so all portfolio profit opportunities cannot be defined in one meaning, and the best could be defined, with the distributions of its probabilities.

For this reason let's analyze portfolio geometric view again. In the case of traditional portfolio in ordinate axis investment profit is shown as averages of random variables, and in abscise axis - average square deviations of those variables. Following, we have very obvious geometric illustration of the main portfolio analysis results. It is emphasized that, geometrical evidence do not disappear, if instead of average or dispersions linear functions will be taken. For example, we shift them the same in abscise or/and ordinate axis, or we can use deviation not from average but from mode and so on.

Let's come back to earlier discussed assumption about portfolio future profitability, investments to be exact, 6 depending on portfolio future profitability non-uniqueness, we have to agree, that in order to define concrete portfolio state, average portfolio profit value is not the very suitable index. Expected or average profitability - that is generalized profit opportunities' state for certain period of time. However, this is only one from other opportunities, which challenge very seldom such a great attention, as that of certain level of quintile (e.g. 95\%) and so on. In every concrete situation, concrete profit will be one from a priori profit opportunities, which are fully defined by their probability distribution. Portfolio profitability, as a random variable defining its opportunities probability distribution interpretation necessity confirm also that case, that as separate investments (bonds, shares, projects and so on), also portfolio price in the market is random variables as well, that don't let confirm that these arc the only expected opportunity (average) estimates. So, the full opportunity view of portfolio profit can be obtained only with the help of random variable as the most adequate logic of this financial-mathematical model [7].

Indeed, interpreting investment portfolio with classical methods, and base on conception of average profit [8], problem of portfolio adequacy for management requirements arises. Talking about profitability average in the future, so this average can be only forecast and quantitatively described, and also only in random variable categories. Such descriptions of portfolio profit opportunities let reveal risk as profit opportunities instability interaction with investor utility function. This is necessary in order to reach systematic risk estimation and adequate formation of its management model.

It is also important to emphasize, that coordinate system, in which further portfolio geometric model will be analyzed, will be conditioned: in ordinate system there will be all opportunity spectrum of random variables (processes) and averages or other functions of those variables possible values Meanwhile, in the abscise axis average standard deviations will be put. That's why analogous to classical (traditional) portfolio facts, as possible portfolio sets, efficiency lines, existence of covering curve and their features and so on, arc correct for the every portfolio profitability opportunity. But in this paper, in order to overview all portfolio profitability opportunities not efficiency line, but entire efficiency zone (Fig 2) will be discussed.

So further portfolio analysis must be moved from sufficiently evident portfolio profit standard deviation and from this profit expected values (averages) coordinate system (Fig 1) to more complex, but also more adequate coordinate system, where in the abscise axis 


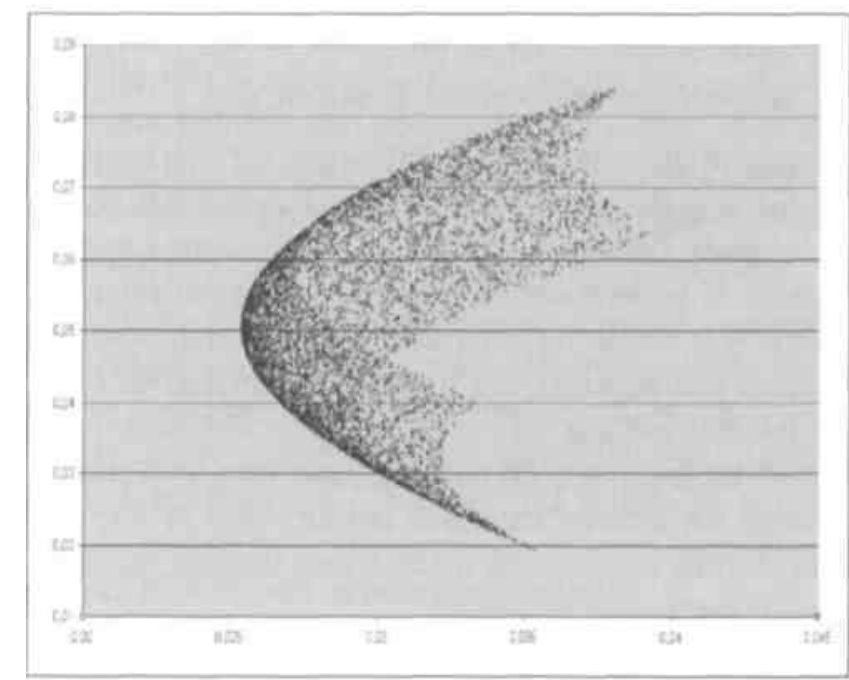

a. View of a classical average-standard deviation portfolio

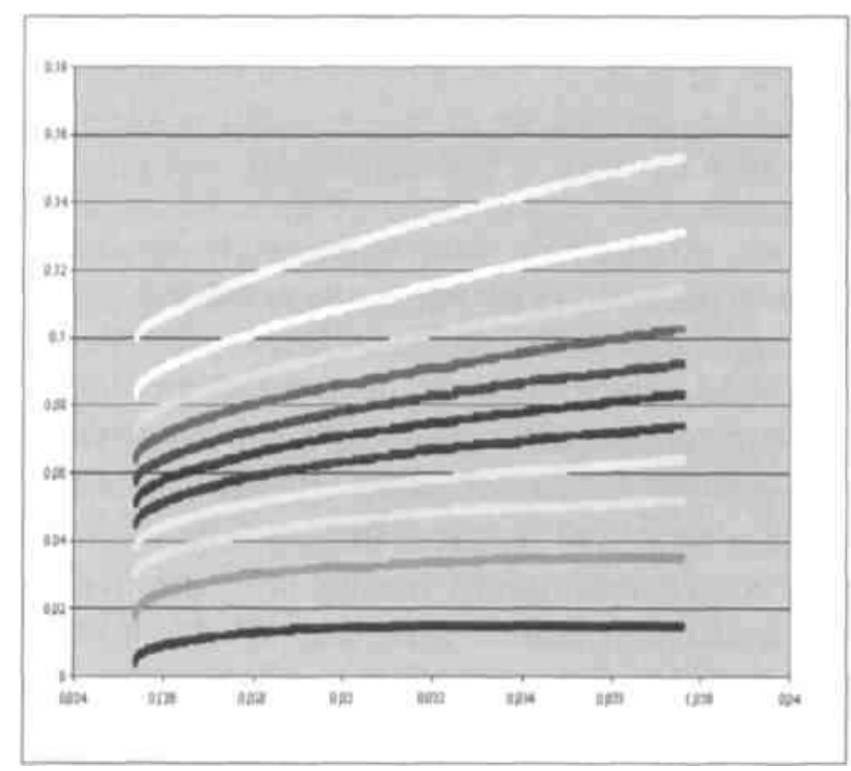

b. Efficiency zone with exceptional minimal and other efficiency lines

Fig 2. Adequacy investment stochastic nature of two liabilities $\left\{I_{1}\left(a_{1}=-0,06 ; \sigma,=0,015\right) ; 1_{2}^{\prime}\left\{\alpha_{2}^{\prime}=-0,08 ; \sigma_{2}\right.\right.$ $=0,019))$ and two kinds of assets $\left(/,(</,=0,1 ; \sigma,=0,03) ; l_{2}\left(a_{2}\right.\right.$ $\left.\left.=0,144 ; \sigma_{2}=0,035\right)\right)$ portfolio

there are portfolio profit average standard deviations, and in the ordinate axis correspondingly there is efficiency zone (Fig 2b), which consists of all quintile efficiency lines. In Fig $2 b$ opportunity minimum and all deciles efficiency lines are given in a classical portfolio, geometrical view of which is given in the Fig 2a. It's obvious, that on the whole, efficiency zone is a continually fulfilled plane surface between minimal and maximal quintiles.

More fully portfolio anatomy is shown in the Fig 3, in which portfolio profitability opportunity spectrum is given ( $\mathrm{X}$ axis) and risk ( $\mathrm{Y}$ axis), and probability distributions, defining, how portfolio profitability opportunities are located, when different portfolio risk levels exist ( $\mathrm{Z}$ axis). Possibility to know reliability level of each quintile enables to use directly the utility function of the portfolio owner, by creating complex portfolio selection for the owner scheme, in which there will be taken into account full portfolio opportunity spectrum and its risk, and also investor utility function.

In order to provide quicker understanding of complex investment portfolio risk analyses schemes, we will collate modern portfolio analysis scheme with complex scheme. According to a classical modern portfolio theory investor should be interested only in those portfolios, which are located on the efficiency line. Efficiency line itself here is understood as maximal expected profits (averages), obtained for concrete portfolio set average standard deviation variable, complex of values. Possible portfolios set in a classical scheme is formed in all possible ways, in all possible proportions connecting all existing investments into one portfolio and for all so formed portfolios profit average (expected value) and average standard deviation is evaluated.

But in reality, investments, i.e. profitability is watched and realized not in its averages, but in some possible values, which are defined by investment market and obtaining price. That's why it is important for the investor to see full possible portfolio profit opportunities set, but not only portfolios that are in average efficiency line. So, an investor is interested in entire efficiency zone, which is understood as the complex of efficiency lines for selected investments for all combinations of possibilities. In this way, analysis of

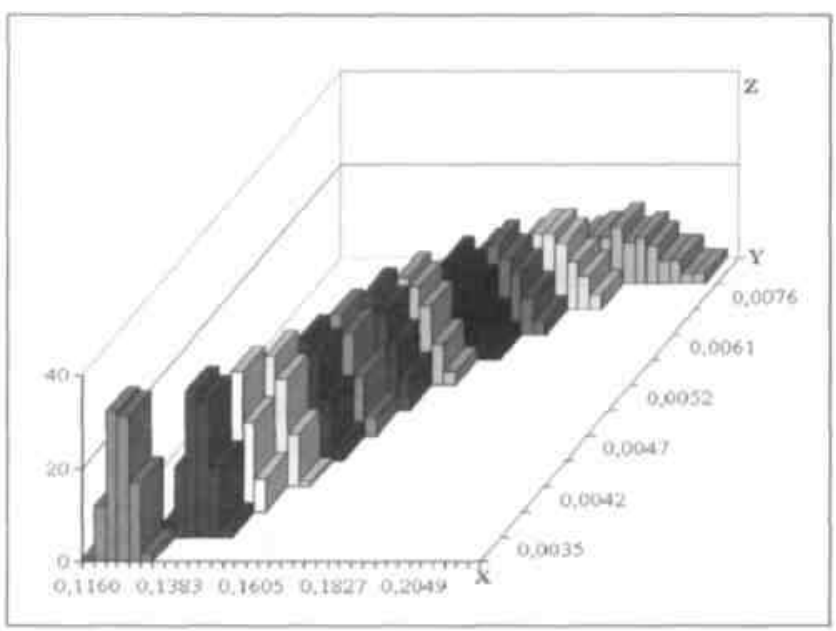

Fig 3. Portfolio anatomy for adequate investment profitability stochasticity 
efficiency lines, where those portfolios are located, which have average maximum, for each value of possible portfolio set average standard deviation, is changed into efficiency zone analysis. In its turn, indifference curve of investors must be changed (developed) by utility functions.

Summarizing, it's important to emphasize ones again those main differences, which accrue while using classical (modern) portfolio theory and here suggested portfolio theory that is adequate investment profitability for stochastic nature (see the Table 1).

Table 1

\begin{tabular}{|c|c|}
\hline Classical portfolio theory & Adequate portfolio theory \\
\hline $\begin{array}{l}\text { - Defines efficiency line, in which } \\
\text { existing portfolios have to maximize } \\
\text { expected (average) profitability } \\
\text { between all given risk portfolios from } \\
\text { possible portfolios set; } \\
\text { - Indifference curve of each investor } \\
\text { lets them to select portfolio, in which } \\
\text { investor can reach maximum of } \\
\text { average profitability } \\
\text { - Do not analyze the result reliability. }\end{array}$ & $\begin{array}{l}\text { - Defines efficiency zone, in which for } \\
\text { every possible portfolios set risk level } \\
\text { is maximal opportunities probability } \\
\text { distribution; } \\
\text { - Utility function of every investor lets } \\
\text { to choose such a risk level, and also } \\
\text { such a maximal opportunities } \\
\text { distribution, which maximize use of } \\
\text { investor } \\
\text { - Orientated to evaluation of result } \\
\text { reliability. }\end{array}$ \\
\hline
\end{tabular}

\section{Choosing of integral liabilities and assets portfolio, in order to reach comparison of optimal profitability and risk}

\section{Integral portfolio of four kinds of liabilities and} four kinds of assets. The main coordination, of each financial institution, providing loans and lending capital for the further borrowing of liabilities and assets structures change, is such which could guarantee current and strategic goals putting into practice. In its turn, the strategic goal of the institution, which often is understood as increase of value of that institution, directly base on permanent rule, that asset and liability portfolio will guarantee desirable profitability, taking into consideration risk management opportunities.

In literature a lot of aspects, ways and instruments of asset and liability portfolio management arc analyzed. One of the most finished ways that have concrete solving instruments is interest rate risk management. If not managed, interest rates, can de dangerous for the institution's income and capital, because interest rate changes influence institution income and its economical value.

For the evaluation of interest rate risk influence, usually these indexes are used:

- Net interest income;

- Net interest margin;
- Difference of interest rate;

- Interest gap and interest financial gap.

To analyze interest rate risk influence for the institution income there net interest and net interest margin conceptions (models) will be used. Net interest incomes - is understood as difference between interest income (for loans, for securities and so on) and interest costs (for deposits, for long-term loan and so on). Net interest margin - is understood as difference of interest income, interest earning asset unit, and interest costs for interest expenses liability unit or the relationship of net interest income and interest income earning asset.

Interest rate risk influence evaluation by net interest income and net interest margin and management of this influence is especially important moment for choosing and management of liabilities and assets structure of financial institution [9]. Unfortunately, in many cases the solution of this important problem is done with the help of intcrdependently not related evaluations, according to separate criteria. Meanwhile, common efficiency of liabilities and assets, which could be measured in net interest income or net interest margin, taking into consideration also liability and asset risks, which often are interrelated, are direct management goal of financial institution, that require such instruments which integrate efficiency and risk.

The best solution of analogous problem, which developed in investment theory, is using of modern (classic) investment portfolio idea. Undoubtedly, investment portfolio idea and result of practical use can be used directly in creating mechanism of integrated asset and liabilities and their risk management. It means, that formed common asset and liability portfolio, adequate to asset and liability common efficiency, analyzing of full opportunity spectrum and seeking for optimal solution. Further this portfolio will be called portfolio of integral asset and liability opportunities investigation, or just integral portfolio.

For deeper understanding of integral portfolio anatomy it is important to remember the main features of modern investment portfolio and adequate investment profit stochastic portfolio. To understand why integral portfolio obtains one or another geometric form, better to remember, that it formed as peculiar asset (investments) portfolio and liability portfolio composition (Fig 2). Now, integral portfolio will be analyzed, which is formed from four liabilities - 1, $(3,=-0,04$, $\sigma,=0,002), \mathrm{I}_{2}\left(\mathrm{a}_{2}=-0,05, \sigma_{2}-0,0027\right), \mathrm{I}_{3}\left(\mathrm{a}_{3}=-0,006, \sigma_{3}\right.$ $=0,0033), \mathrm{I}_{4}\left(\mathrm{a}_{4}=-0,07, \sigma_{4}=0,004\right)$ and four kind of assets $\mathrm{I}_{5}\left(\mathrm{a}_{5}=0,098, \sigma_{5}-0,006\right), \mathrm{I}_{6}\left(\mathrm{a}_{6} \ll 0,12, \sigma_{6}=\right.$ $0,007), \mathrm{I}_{7}\left(\mathrm{a}_{7}-0,14, \sigma_{7}=0,007\right), \mathrm{I}_{8}\left(\mathrm{a}_{8}=0,17, \sigma_{8}-\right.$ 
0,013). Its geometrical view is in Fig 4. To form integral portfolio such conditions where allowed: that common liability and common asset extent coincide, and that both asset and liability opportunities obey for the normal distributions with the averages - a and standard deviations - $<5_{l}$ shown in the brackets.

The geometrical view of integral portfolio witnesses that (Fig 2 and Fig 4) its utility logic should be similar to classical investment portfolio logic. But evidently, every method and result of classical portfolio should be checked. The integral portfolio studies should enable new interpretation or even supplement results of classical investment portfolio.

It also become clear some integral portfolio features, if compared it with the classical investment portfolio. As it is known, in a classical portfolio possible portfolio sets tops absolutely coincide with base investment, i.e investment, which can not be expressed as linear combinations of other investment, by using structure coefficients - w, coordinates - standard deviation and average.

In the case of integral portfolio tops coincide, for example, average square deviation and average interaction description portfolio, with asset and liability pair sums coordinates.

However, for these portfolios, in which standard deviation and other portfolio efficiency index opportunities distribution characteristics, for example minimum or maximum are analyzed, such evidence does not exist.

Internationalization of investment portfolio. During the period of globalization and market integration conditions, not only multinational, but also national corporations must dispose of different currencies and of other financial assets of different countries. For all corporations - for multinational and national - very important is to formulate rationally multi- exchange portfolio of assets and liabilities. Undeniable, that corporation's ability to choose and manage properly currency portfolio is the problem of priority, with which corporation financial managers deal. To make up and manage such kind of portfolio, problems of different aspects arise.

Here we will analyze the problem and procedure of making up and choosing currency portfolio, by solving problems in a described situation. Let's say that, large corporation's, existing in one of the countries in the Eurozone, one of departments dispose of $1 \mathrm{mln}$. EUR capital, which could be invested for one year period. Meanwhile, other department after one year will have to borrow $1 \mathrm{mln}$. EUR, for the purpose to fulfill its international operations. A large commercial bank, working in Euromarket, agrees to accept deposits in currencies and suggests more favorable interests for deposits in currencies, then in this period is going to be interests for deposits in Euro. The bank also pledges to return accumulated sum in wanted currency structure, taking into consideration currency exchange rates at that moment.

The banks suggested currency interest rates per year, and future currency exchange rate after one year, at the moment can be evaluated only as random variables, possible meaning probabilities of which are shown in the Table 2.

Banks suggested average interest rate for different currency deposits and forecasted currency rate changes in one year Table 2.

Table 2

\begin{tabular}{|c|c|c|}
\hline Currency & $\begin{array}{c}\text { Forecasted interest rate for } \\
\text { year }\end{array}$ & $\begin{array}{c}\text { Forecasted changes of } \\
\text { exchange rate in Euro }\end{array}$ \\
\hline USD & $\mathrm{N}(0.07 ; 0,001)$ & $\mathrm{N}(+0,1 ; 0,001)$ \\
\hline JY & $\mathrm{N}(0.1: 0.0014)$ & $\mathrm{N}(-0,15: 0,0075)$ \\
\hline GBP & $\mathrm{N}(0.09 ; 0.0012)$ & $\mathrm{N}(+0,05 ; 0,008)$ \\
\hline RUB & $\mathrm{N}(0,14 ; 0.01)$ & $\mathrm{N}(-0,25 ; 0,009)$ \\
\hline
\end{tabular}

What kind of portfolio of corporations' deposits in currencies should be, which could maximize accumulated sum S, measured in Euro, corporations' usefulness coefficient $U=u\left(S, o_{s}\right)$. Here $o_{s}$ - average standard deviation, index of riskiness. In the schemes $5 \mathrm{a}$ and $5 \mathrm{~b}$ possible portfolio sets are given, when those portfolios are made up investments possibilities distribution measure - average standard deviation, and correspondingly, description of those opportunities minimal and maximal dependence.

Exteriorly negligible differences minimal and maximal portfolio sets predetermine that investments to USD, JY, GBP and RUB became slightly "similar". It means, having analogous dependencies of minimal and standard deviation, and maximal with standard deviation.

But in order to ensure that all set of possible portfolios are not heterogeneous, can be done by watching (5c scheme) how quickly the structure of optimal portfolio is changing, even when not so significantly changes the co-ordinates of portfolio average standard deviations and in average surface. That's shown by the points $\mathrm{M},\left(\mathrm{w},=0,24 ; \mathrm{w}_{2}=0,2 ; \mathrm{w}_{3}=0,4 ; \mathrm{w}_{4}=0,16\right)$, $\mathrm{M}_{2} \quad\left(\mathrm{w},=0,4 ; \quad \mathrm{w}_{2}=0,12 ; \quad \mathrm{w}_{3}=0,48 ; \quad \mathrm{w}_{4}=0\right)$ and $\mathrm{M}_{3}$ $\left(\mathrm{w},=0,72 ; \mathrm{w}_{2}=0 ; \mathrm{w}_{3}=0,28 ; \mathrm{w}_{4}=0\right)$. In the brackets those parts are shown, by which investments in USD, JY, GBP and RUB comprise the portfolio.

Even in this example, for the portfolio maker, conditions are suggested on favorable terms, but the situa- 

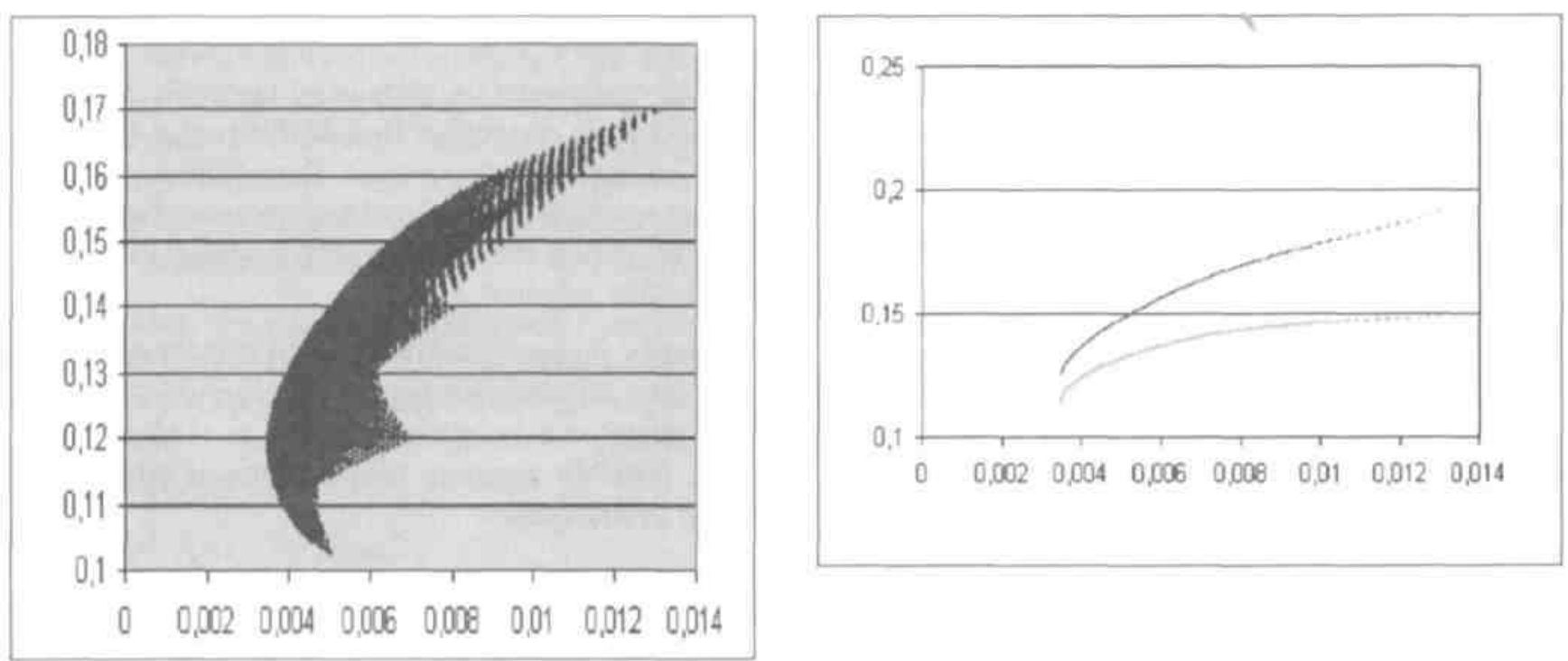

$a_{1}$

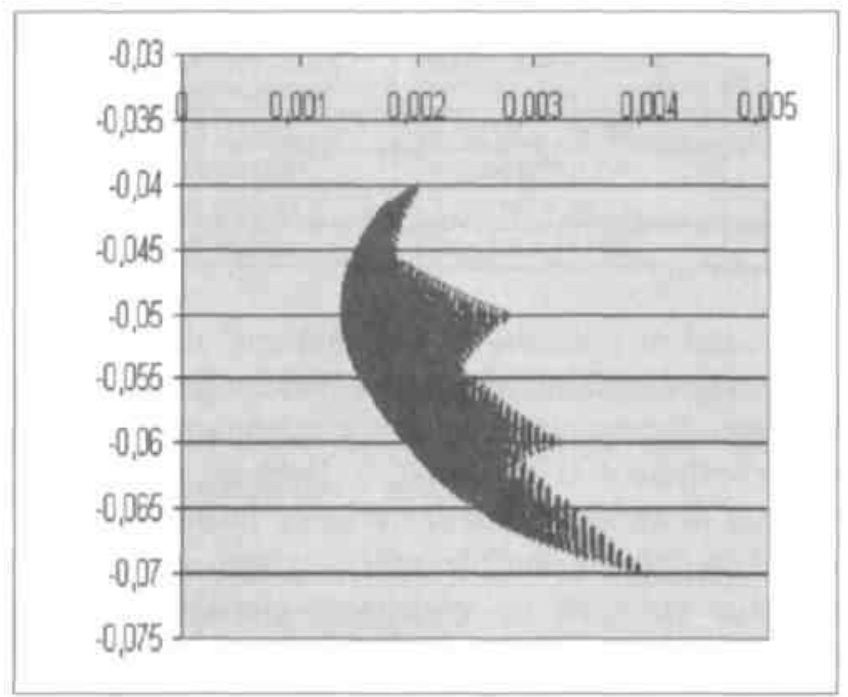

$\mathrm{a}_{2}$

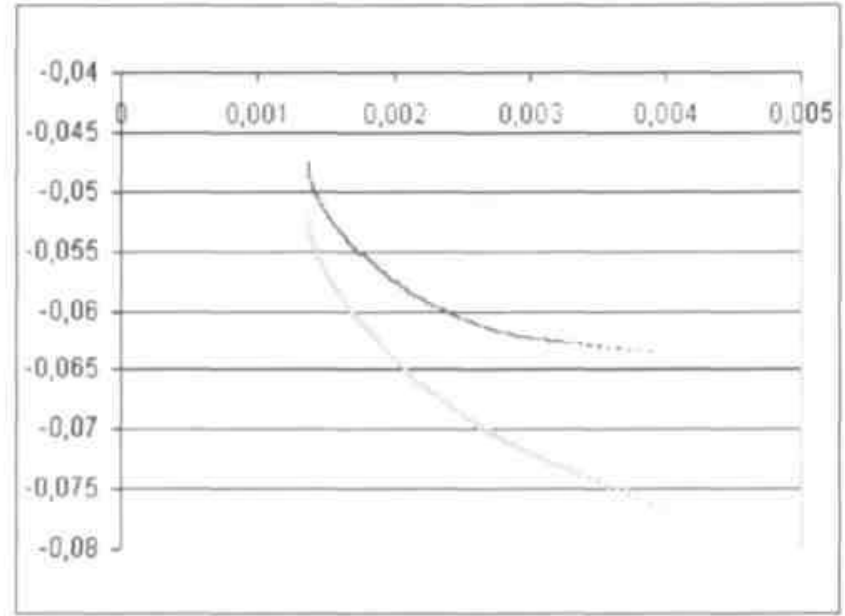

$\mathrm{b}_{1}$

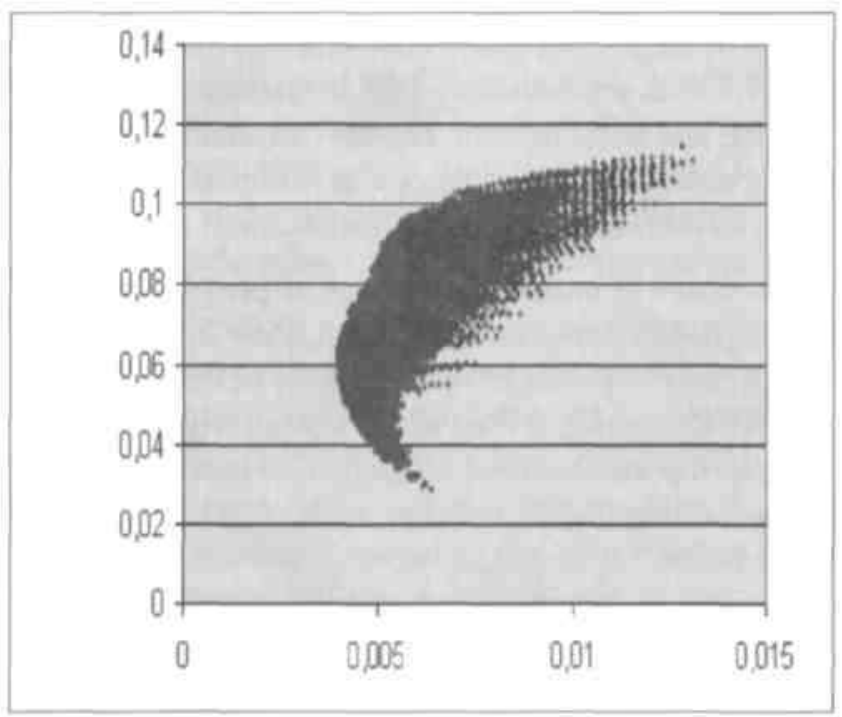

$\mathrm{b}_{2}$

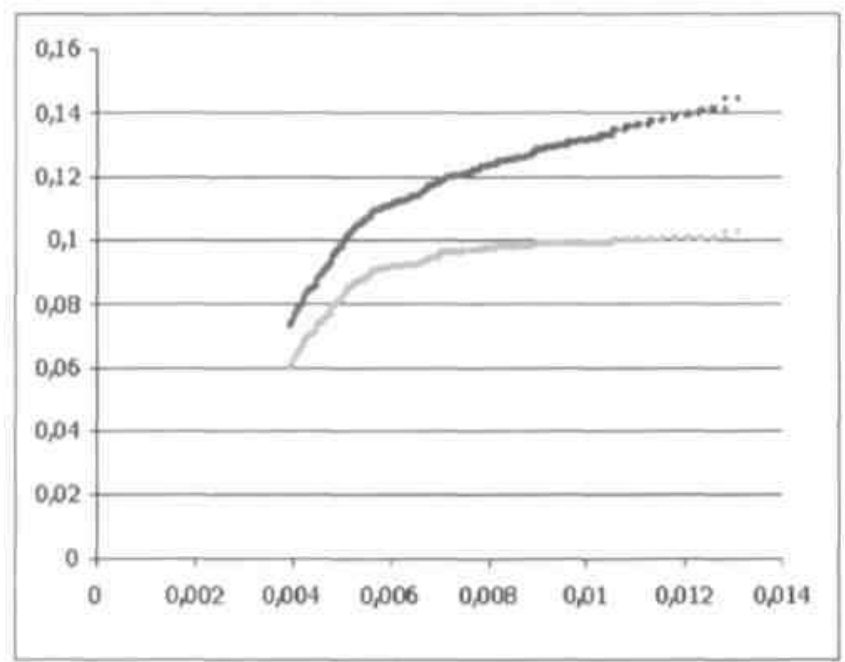

$c_{1}$

$\mathrm{c}_{2}$

Fig 4. The main characteristics of a bank integrated assets and liabilities portfolio: a, an assets portfolio; b, a liabilities portfolio; c, assets and liabilities integrated portfolio; $a_{2}, b_{2}, c_{2}$ Efficiency zone of these portfolios 


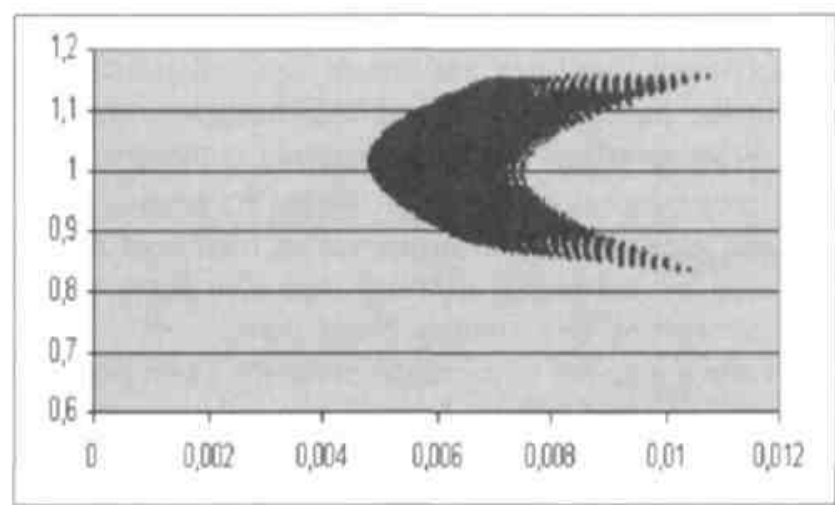

a

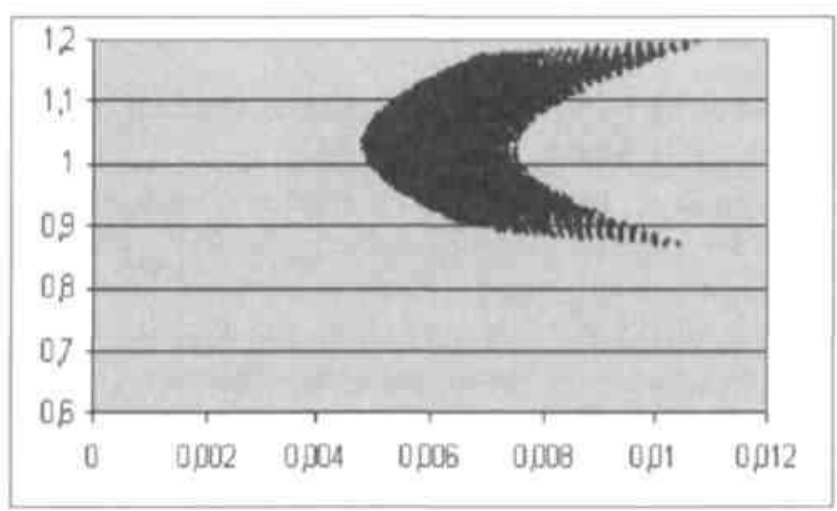

b

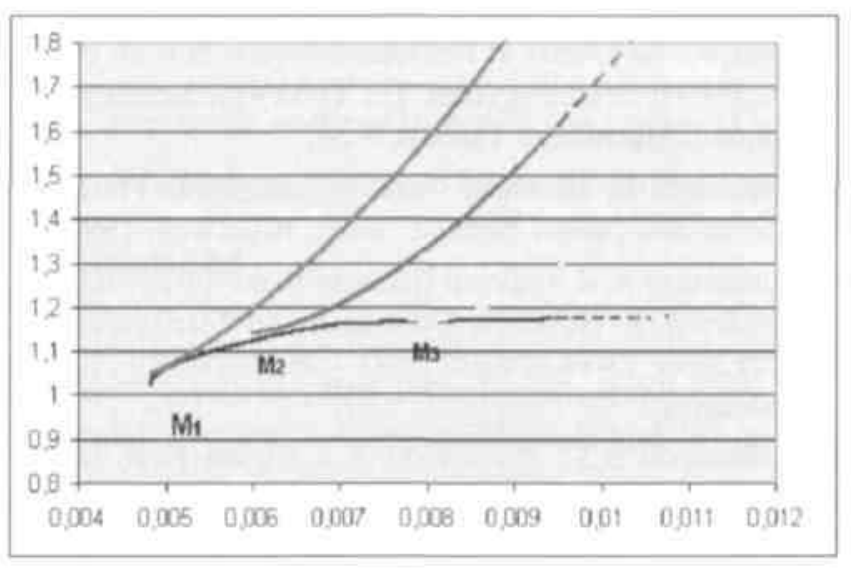

C

Fig 5. The fragment of four currencies (USD, JY, GBP, RUB) portfolio which maximize accumulated sum: $a, b$ the subsets of portfolios when they present consequently minimum and maximum profitability possibilities, if to take in account their depending on standard deviation; c optimal portfolios for three investments $M, M_{.,} M_{3}$ on the standard deviation-mean value line.

tion on the whole is very typical or simply is a component of different situations, in which additional restrictions exist. The ability to manage this situation properly should help in making analysis of much more complex problems. Further portfolio of two currencies will be analyzed. Regardless of, at a first sight very elementary situation, this situation itself is met as a component of more complex problems or even autonomic. By the way, the formation of portfolio itself not always is clear and easy technically reachable.

The portfolio of two currencies. After Litas was unlocked from USD and pegged to EUR a big part of people permanently solve very actual problem nowadays - investor problem, in what currency LTL or USD to keep one's savings, so that time and risk as least as possible decreased the value of accumulated money, or how to find opportunity to raise it's value. For every individual saver the value of accumulated sum very often is measured by its purchasing power.

Further, the solution of problems that arise in this situation will be analyzed. Let's say, that an individual intends to invest the savings 100000 LTL to a saving accounts in USD and LTL for one year. Probable interest rates in this period are defined by average value $\mathrm{m}$ and standard deviation $\sigma: \mathrm{m}_{\mathrm{USD}}=0,06, \mathrm{O}_{\mathrm{USD}}=0,01$, $\mathrm{m}_{\mathrm{LTL}}=0,085, \theta_{\imath \imath l}=0,025$. By the way, both norms opportunities, probabilities sets will have lognormal probability set form. Probable opportunities of USD rate in litas after one year should obey to normal set $\mathrm{N}(\mathrm{m}=4,1 \mathrm{LTL} ; \sigma=0,03 \mathrm{LTL})$. There should be chosen such a relationship between deposits in USD and LTL, which will maximize the use function $\mathrm{U}=$ $\mathrm{u}\left(\mathrm{S}_{\mathrm{LTL}}, \mathrm{o}_{\mathrm{LTL}}\right)$ of individual, assuring that probability to get at least this maximum will be equal $\gamma(\gamma=3 \%$, $50 \%, 75 \%$ ).

For the solving of this problem, different methods can be used, but for the consumer, evidently, the best understandable should be the ideology of portfolio. By using it earlier formulated task will look like that: to choose the individual investor such a LTL and USD currency portfolio, which satisfy the conditions described in the situation and nominated goals.

In the Fig 6 illustration of solving this problem is given.

Portfolio of two investments - that is certain curve of accumulated sum opportunities and their standard deviation in a coordinate surface. The portfolio of two investments is exceptional in respect with that facts, that its effective line coincides with the upper part of that portfolio $\left(6^{\text {th }}\right.$ scheme). In the $6^{\text {th }}$ scheme a very original map of portfolio and investment possibilities interaction is shown. Here are two effective lines: $1^{\text {st }}$ assure $3 \%$, and $2^{\text {nd }}-75 \%$ reliability levels let choose different portfolios, for the investors accepting different risk. Those are points $\mathrm{P}_{\mid \mathrm{p}} \mathrm{P}_{\mathrm{p}}, \mathrm{P}_{21} \mathrm{P}_{22}$. Upper points $\mathrm{Pj}$ - index define, what portfolio structure should be, what are $\mathrm{w}$, ir $\mathrm{w}_{9}$ values. This map - is some kind of portfolio view in a $5 \mathrm{~d}$ view: portfolio risk (abscise 


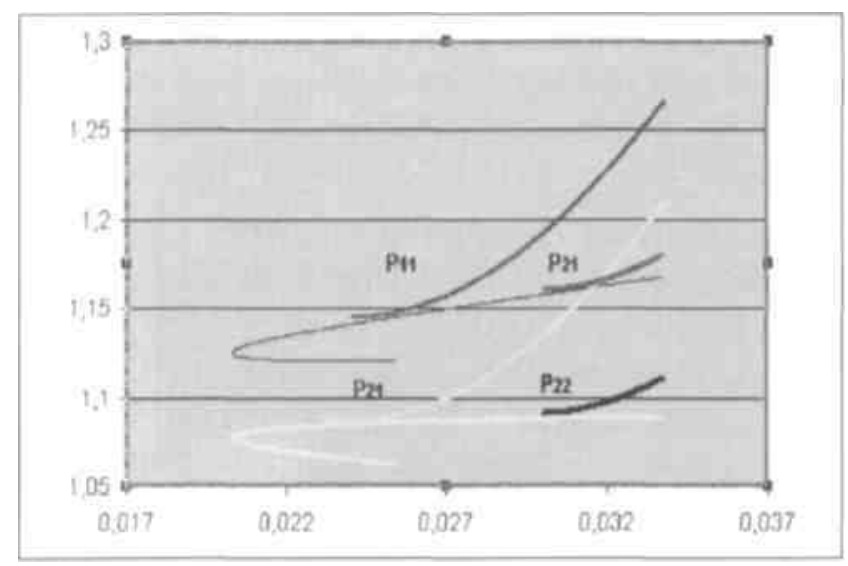

Fig 6. The map of interaction between two currencies portfolio possibilities and investor utilities is shown

value), the size of accumulated sum (ordinate value), reliability value (reliability level of effective line), usefulness of portfolio (calculated using use function), portfolio structure (w, values).

\section{Conclusions and suggestions}

- Concrete financial solutions always have to be directed to future and this condition is the reason predetermining, that a lot of parameters are not known having one meaning, but only opportunity spectrum is known. That's why, when indetermination or risk exist, solutions have to be made and that require new information regulation principals and method of accepting solution. In the paper one of possibilities is given how the main company budget should be made, in respect with stochastic information.

- In a market conditions a lot of optimization tasks are solved not only in order to reach extreme optimizing sizes - profit, part of market and similar values, assuring guarantee of or another value. Principles analyzed in the paper and reached method how investment portfolio, adequate to stochastic investment income nature, should be formed and calculated.

- It is very important company's, especially finance, management moment that is assets and li- abilities management and, first of all, formation of those liabilities and assets optimal portfolio. In the paper very original integral assets and liability portfolio choosing method is suggested. - Taking into consideration always increasing risk and indetermination influence on results of business or individual activity and also increasing number of risk management instruments, it is very important to organize properly a company's accounts and other information regulation, which let accept rational decisions in respect with risk management possibilities.

\section{References}

1. Markowitz H. M. Portfolio Selection. Journal of Finance 7(1). March, 1952, p. 77-91.

2. Rushinek A., Rushinek S.F. Forecasting sales, expenses and stock market values by quarterly financial statement ratio analysis. Managerial Auditing Journal. ISSN 02686902. MCB University press, 1995 , Vol 10, No 2, p. 733.

3. Sharpe W. F. A Simplified Model for Portfolio Analysis. Management Science, January 1963.

4. Rutkauskas A.V., Rutkauskas V. Investment management under risk and uncertainty. Real estate valuation and investment, 1998, No 2 (4), p. 47-57.

5. Tobin J. The Theory of Portfolio Selection in F. H. Hahn and F R. P. Brechling (eds), The Theory of Interest Rate. London, Macmillan, 1965, p. 3-51.

6. Markowitz H. M. Mean Variance Analysis in Portfolio Choice and Capital Markets. Basil, Blackwell, 1990.

7. Rutkauskas A.V. Regional Business Risk Monitoring. In: Conference "Business Contracts and Management" LITEXPO, 13-14 of April 2000. Vilnius, 2000. 17 p. (in Lithuanian).

8. Ziobrowski B.J., Ziobrowski A.J. Higher Real Estate Risk and Mixed-Asset Portfolio Performance. Journal of Real Estate Portfolio Management, Volume 3, Number 2, 1997, p. 107-115.

9. Black F and Sholez M. The Pricing of Options and Corporate Liabilities. Journal of Political Economy, 81(3) May/June 1973. 